\title{
accD nuclear transfer of Platycodon grandiflorum and the plastid of early Campanulaceae
}

\author{
Chang Pyo Hong ${ }^{1}$, Jihye Park², Yi Lee ${ }^{3}$, Minjee Lee², Sin Gi Park', Yurry Uhm, Jungho Lee ${ }^{2^{*}}$ and Chang-Kug Kim ${ }^{5^{*}}$
}

\begin{abstract}
Background: Campanulaceae species are known to have highly rearranged plastid genomes lacking the acetyl-CoA carboxylase (ACC) subunit D gene ( $\operatorname{ccc} D)$, and instead have a nuclear ( $\mathrm{nr}$ )-accD. Plastid genome information has been thought to depend on studies concerning Trachelium caeruleum and genome announcements for Adenophora remotiflora, Campanula takesimana, and Hanabusaya asiatica. RNA editing information for plastid genes is currently unavailable for Campanulaceae. To understand plastid genome evolution in Campanulaceae, we have sequenced and characterized the chloroplast (ср) genome and $\mathrm{nr}-\mathrm{accD}$ of Platycodon grandiflorum, a basal member of Campanulaceae.

Results: We sequenced the 171,818 bp cp genome containing a 79,061 bp large single-copy (LSC) region, a 42,433 bp inverted repeat (IR) and a 7840 bp small single-copy (SSC) region, which represents the cp genome with the largest IR among species of Campanulaceae. The genome contains 110 genes and 18 introns, comprising 77 protein-coding genes, four RNA genes, 29 tRNA genes, 17 group II introns, and one group I intron. RNA editing of genes was detected in 18 sites of 14 protein-coding genes. Platycodon has an IR containing a 3' rps 12 operon, which occurs in the middle of the LSC region in four other species of Campanulaceae ( $T$. caeruleum, A. remotiflora, C. takesimana, and H. asiatica), but lacks accD, $C I P P$, infA, and rpl23, as has been found in these four species. Platycodon nr-accD contains about $3.2 \mathrm{~kb}$ intron between nr-accD.e1 and nr-accD.e2 at the same insertion point as in other Campanulaceae. The phylogenies of the plastid genomes and $a c c D$ show that Platycodon is basal in the Campanulaceae clade, indicating that IR disruption in Campanulaceae occurred after the loss of $a c c D, c l p P$, infA, and rpl23 in the cp genome, which occurred during plastid evolution in Campanulaceae.
\end{abstract}

Conclusions: The plastid genome of $P$. grandiflorum lacks the rearrangement of the IR found in $T$. caeruleum, A. remotiflora, C. takesimana, and $H$. asiatica. The absence of $a c c D, C / p P$, infA, and rpl23 in the plastid genome is a synapomorphic characteristic of Campanulaceae. The chloroplast genome phylogeny supports the hypothesis that chloroplast genomic arrangement occurred after accD nuclear transfer and loss of the four genes in the plastid of early Campanulaceae as a lineage of asterids.

Keywords: accD, Campanulaceae, Genomic rearrangement, Intron loss, Nuclear gene transfer, Plastid

\section{Background}

Plastid organization is highly conserved among angiosperms. Most angiosperm plastids have a quadripartite structure with two copies of a large inverted repeat (IR) separated by small (SSC) and large (LSC) single-copy

\footnotetext{
*Correspondence: jlee@greenplant.re.kr; chang@korea.kr

${ }^{2}$ Green Plant Institute, B-301, Heungdeok IT Valley, Giheung-gu, Yongin 446-908, South Korea

${ }^{5}$ Genomics Division, National Institute of Agricultural Science (NAS), RDA, Jeonju 560-500, South Korea

Full list of author information is available at the end of the article
}

regions. The two copies of the IR facilitate flip-flop recombination, resulting in the presence of isoforms that differ in the orientation of the single copy regions. The early electron microscopic comparisons revealed that plastid genomes are circular in either monomeric or multimeric forms [1]. Substantial recent evidence suggests that the plastid genome has a more complex structure, with circular, linear, branched, and multimeric configurations that vary during plastid development [2-7].

Inverted repeat expansion and contraction occur in the plastid genome of land plants via a boundary shift of 
the border regions of IR/LSC and IR/SSC. In addition to these IR boundary shifts, there are a few cases where the IR has been severely reduced or even eliminated [8-13]. The major shift of the IR in the Campanulaceae species Hanabusaya and Trachelium provides examples of SCto-IR transitions for six genes (ycf1, rps15, ndhH, ndhA, $n d h I$, and $n d h G$ ), with the exception of the $3^{\prime}$ rps12 operon and IR-to-SC transitions for five of the six ancestral IR genes [13].

The majority of plastid genes are contained in operons and transcribed as poly-cistronic units, a feature that originated from a cyanobacterial ancestor. In angiosperm plastids, disruption of operons has been documented in three angiosperm families: Campanulaceae [14-16], Geraniaceae $[10,17]$, and Fabaceae [18-21]. In Campanulaceae, the plastomes have two disrupted operons: the rps2 operon (rps2 - atpI - atpH - atpF - atpA) and the $\operatorname{clpP}$ operon (clpP - 5' rps 12 - rpl20) $[15,16]$. In both cases, the relocated segments of the operons must have acquired new promoters to be transcribed; however, experimental studies have not been performed to determine how these segments are transcribed in their new locations [22].

The nature of the IR reduces the substitution rate. Zhu et al. [13] demonstrated that synonymous substitution rates are, on average, 3.7 times slower in IR genes than in SC genes, and that genes moved from the SC into the IR exhibit lower synonymous rates consistent with other IR genes, whereas genes moved from the IR into the SC exhibit higher rates consistent with other SC genes; the exceptions being in Pelargonium (Geraniaceae), Plantago (Plataginaceae), and Silene (Caryophyllaceae). In this paper, they used the comparison of the species Hanabusaya and Trachelium of Campanulaceae as the most illustrative single example of the effect of IR duplication on substitution rates.

Although many gene losses have been documented in angiosperms $[23,24]$, only a few of these events have been rigorously investigated [22]. It is widely known that plastid DNA is transferred to the nucleus at a high rate [25-27]; however, only a few functional gene transfers to the nucleus have been characterized in angiosperms.

The acetyl-CoA carboxylase (ACC) subunit D gene $(a c c D)$ is known to be essential for leaf development in angiosperms [28]. The $a c c D$ gene has been lost at least in seven times in angiosperm plastid genomes including Poales [29-31], Acoraceae [32, 33], Geraniaceae [34], Fabaceae [24], Campanulaceae [33], Oleaceae [35], and Rafflesiaceae [36]. In Trifolium, one copy of this gene was found in the nucleus [24]. In grasses, the prokaryotic multisubunit enzyme has been replaced by a plastid-targeted eukaryotic ACC [37, 38].

Campanulaceae, including Lobeliaceae (sensu APG III 2009), have experienced a high degree of gene order change. Although only one plastome sequence, that of
Trachelium caeruleum [16], has been published, draft genomes have been completed for several other genera [15], and restriction site and gene maps have been published for many others [39, 40]. The most extensive comparisons have included gene maps for 18 genera of Campanulaceae [22, 39], where the authors estimated that the changes in gene order were due to a minimum of 42 inversions, 18 large insertions $(>5 \mathrm{~kb})$ of unknown origin, five IR expansions and contractions, and several putative transpositions [22]. The complete genome sequence of Trachelium [16], the least rearranged taxon examined by Cosner et al. [39], confirmed that at least seven inversions are present in this genome, but it did not provide any evidence of transposition as a mechanism underlying the observed changes in gene order [22].

Recently, Rousseau-Gueutin et al. [33] showed that the chloroplast acetyl-CoA carboxylase subunit $(a c c D)$ gene present in the plastome of most angiosperms has been functiona.

lly relocated to the nucleus in Campanulaceae, and they experimentally verified the presence of a chloroplastic transit peptide by showing that the product of the nuclear $a c c D$ fused to green fluorescent protein was imported in the chloroplasts. As noted above, Campanulaceae are known to have highly rearranged plastid genomes lacking $a c c D$, and instead they have an nr-accD. Plastid genome information has been thought to mainly depend on studies concerning T. caeruleum. More recently, the plastid genomes of Adenophora remotiflora, Campanula takesimana, and Hanabusaya asiatica have been sequenced [41-43]. We have characterized the plastid genome of the Campanulaceae species Platycodon grandiflorum cultivar Jangbaek-doraji, as part of a genome project funded by the National Agricultural Genome Center of the Korean Government. As RNA editing information for plastid genes is currently unavailable in Campanulaceae, we also characterized plastid RNA editing in P. grandiflorum. To understand plastid genome evolution in Campanulaceae, we have characterized and compared the cp genome and nr-accD of $P$. grandiflorum with those of known taxa.

\section{Results and discussion}

\section{Genome organization and features of Platycodon grandiflorum}

The general features and plastid genomic structure of $P$. grandiflorum were compared with those of A. remotiflora, C. takesimana, H. asiatica, and T. caeruleum (Campanulaceae) (Tables 1 and 2). The overall GC content of the $P$. grandiflorum genome is low (38.12\%), which is similar to that of $A$. remotiflora (38.76\%), C. takesimana (38.80\%), $H$. asiatica (38.76\%), and T. caeruleum (38.33\%). There are 140 genes in the $P$. grandiflorum plastid genome, which is 14 to 19 genes more than identified in A. remotiflora, $C$. takesimana, T. caeruleum, and $H$. asiatica. The length of 
Table 1 General features of the plastid genomes in Campanulaceae species

\begin{tabular}{|c|c|c|c|c|c|}
\hline & Platycodon & Hanabusaya & Trachelium & Campanula & Adenophora \\
\hline Length & 171,818 & 167,287 & 162,321 & 169,551 & 171,724 \\
\hline GC contents (\%) & 38.12 & 38.76 & 38.33 & 38.80 & 38.76 \\
\hline No. of Genes & 140 & 129 & 126 & 126 & 126 \\
\hline No. of Conserved CDS & 95 & 83 & 80 & 83 & 82 \\
\hline No. of tRNA & 37 & 36 & 36 & 35 & 36 \\
\hline No. of rRNA & 8 & 10 & 10 & 8 & 8 \\
\hline No. of Introns & $|(1)| \mid(24)$ & $\mid(1) \|(23)$ & $\mid(1) \|(23)$ & $\mid(1) \|(23)$ & $\mid(1) \|(22)$ \\
\hline Coding density & 59.35 & 52.49 & 46.87 & 53.60 & 51.43 \\
\hline CDS + strand & 38 & 44 & 47 & 48 & 40 \\
\hline tRNA + strand & 22 & 18 & 18 & 18 & 20 \\
\hline rRNA + strand & 4 & 5 & 5 & 4 & 4 \\
\hline CDS - strand & 57 & 39 & 33 & 35 & 42 \\
\hline tRNA - strand & 15 & 18 & 18 & 17 & 16 \\
\hline rRNA - strand & 4 & 5 & 5 & 4 & 4 \\
\hline Percent of $+/-$ & 45.71 & 51.94 & 55.56 & 55.56 & 50.79 \\
\hline
\end{tabular}

the plastid genome in P. grandiflorum is $171,818 \mathrm{bp}$, and the genes account for a coding density of $59.3 \%$ of the total cp genome sequence. The latter value is the highest coding density among all reported Campanulaceae species to date. These results indicate that the $\mathrm{cp}$ genome of $P$. grandiflorum is more compact than those of the other species considered.

In the cp genome of $P$. grandiflorum, there is a biased gene distribution over the two DNA strands, with 38 (40\%) conserved genes occupying one strand $(+)$ and 57 genes occupying the other strand (-) (Table 1). The gene contents in one strand were found to be $53,58,57$, and $48 \%$ in the cp genomes of $H$. asiatica, $T$. caeruleum, $C$. takesimana and $A$. remotiflora, respectively. These results indicate that the gene distribution between the two strands of the $P$. grandiflorum cp genome is reversed relative to those of $H$. asiatica, T. caeruleum, C. takesimana and $A$. remotiflora, which have similar values.

The plastid genome sequences of $P$. grandiflorum are assembled as circular molecules of 171,818 bp (Fig. 1 and Table 2) containing a 79,061 bp LSC region, a 42,433 bp IR, and a 7840 bp SSC region. The length of the plastid genome in $P$. grandiflorum (171,818 bp) is $2.5-9.5 \mathrm{~kb}$ longer than that of C. takesimana, H. asiatica, and T. caeruleum, which are between 162,287 and 169,551 bps in length. Campanulaceae plastid genomes are more than $5 \mathrm{~kb}$ longer than the plastid genomes of Asteraceae, Apiaceae, and Araliaceae. The length of the SSC region in Campanulaceae plastid genomes is in the range 7747$8578 \mathrm{bp}$, which is approximately $10 \mathrm{~kb}$ shorter than those

Table 2 Structural comparison of the chloroplast genomes of Platycodon, Hanabusaya, Trachelium, Campanula, and Adenophora of Campanulaceae and other related taxa

\begin{tabular}{|c|c|c|c|c|c|c|c|}
\hline Order & Subfamily & Species & Genome size (bp) & LSC size (bp) & IR size (bp) & SSC size (bp) & GenBank Accession number \\
\hline \multirow[t]{7}{*}{ Asterales } & Campanulaceae & Platycodon grandiflorum & 171,818 & 79,061 & 42,433 & 7840 & KX352462 \\
\hline & & Hanabusaya asiatica & 167,287 & 104,955 & 26,877 & 8578 & NC_024732 \\
\hline & & Trachelium caeruleum & 162,321 & 100,110 & 27,115 & 7981 & NC_010442 \\
\hline & & Campanula akesimana & 169,551 & 102,320 & 29,742 & 7747 & NC_026203 \\
\hline & & Adenophora remotiflora & 171,724 & 105,555 & 27,437 & 11,295 & NC_02699.1 \\
\hline & Asteraceae & Helianthus annuus & 151,104 & 83,530 & 25,295 & 17,576 & NC_007977 \\
\hline & & Lactuca sativa & 152,765 & 84,103 & 25,033 & 18,596 & NC_007578 \\
\hline \multirow[t]{4}{*}{ Apiales } & Apiaceae & Daucus carota & 155,911 & 84,242 & 27,050 & 17,569 & NC_008325 \\
\hline & & Anthriscus cerefolium & 154,719 & 84,774 & 26,197 & 17,551 & NC_015113 \\
\hline & Araliaceae & Panax ginseng & 156,318 & 84,108 & 26,071 & 18,070 & NC_006290 \\
\hline & & Eleutherococcus senticosus & 156,768 & 86,755 & 25,929 & 18,155 & NC_016430 \\
\hline
\end{tabular}




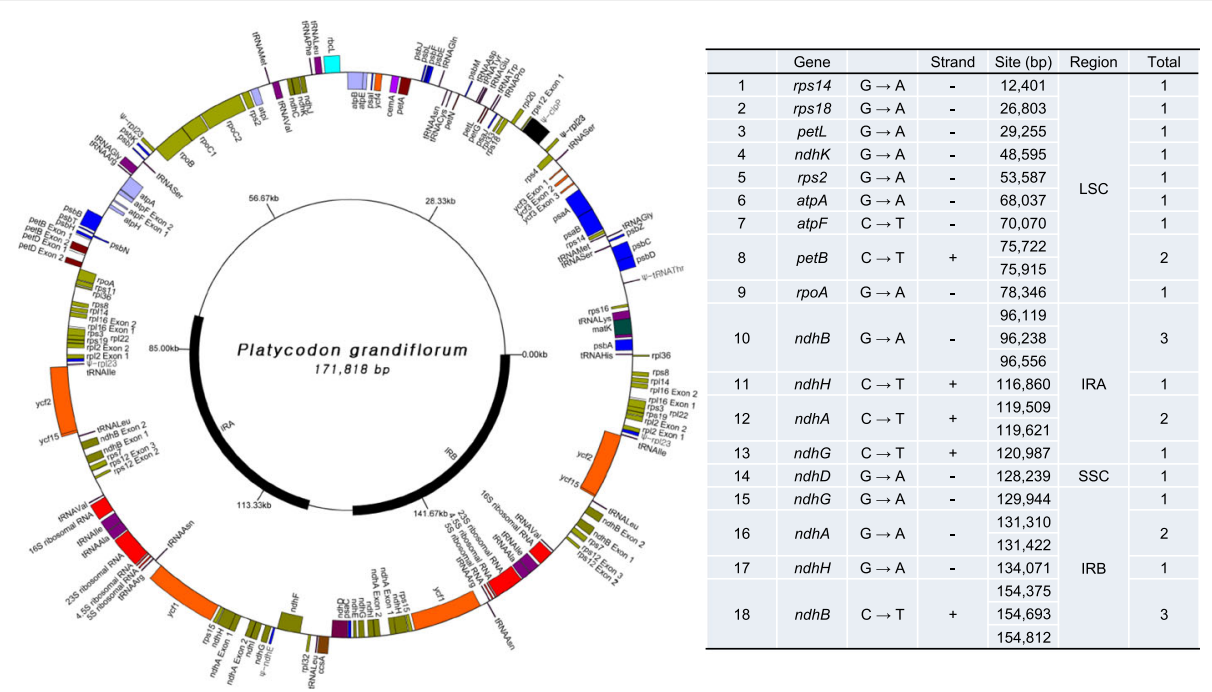

Fig. 1 Plastid genome map of Platycodon grandiflorum cultivar Jangbaek-doraji showing the RNA editing sites. Genes shown on the outside of the circle are encoded on the + strand and transcribed counter-clockwise. Genes on the inside are encoded on the - strand and transcribed clockwise. The relative position of 28 RNA editing sites (19 sites from 14 genes and 7 sites of 4 genes in inverted repeats) is shown in the complete plastid genomic sequence

of Asteraceae, Apiaceae, and Araliaceae. However, the $P$. grandiflorum plastid genome is distinguished from that of other Campanulaceae species in having a $25 \mathrm{~kb}$ longer IR and a $20 \mathrm{~kb}$ shorter LSC region.

\section{Gene contents, RNA editing sites, and cp genome rearrangement in Campanulaecae}

The cp genome of $P$. grandiflorum contains 110 genes and 18 introns, comprising 77 protein-coding genes, four RNA genes, 29 tRNA genes, 17 group II introns, and one group I intron (Additional file 1: Table S1). RNA editing of genes was detected in 25 sites of 14 genes, including seven sites in Inverted Repeat B (Fig. 1). Although there was no variation in the RNA editing sites among RNA samples, samples of RNA other than those of leaf RNA lacked some of the gene transcripts depending on the organ of origin (Additional file 2: Table S2). The 14 genes in which RNA editing was detected include ribosomal small subunit genes (rps2, rps14, and rps18), ATP synthase genes (atpA and atpF), Cytochrome genes (pet $B$ and petL), NADH dehydrogenase genes ( $n d h A, n d h B, n d h D, n d h H, n d h K$, and $n d h G$ ), and RNA polymerase gene (rpoA). In Asteraceae, a total of 373 editing sites were detected in eight plastid genomes, with the average number of 47 sites per species. Among these, 26 sites of 12 genes were conserved in the eight plastid genomes of Asteraceae [44]. The RNA editing in rps18, atpF, petL, $n d h H$, and $n d h K$, found in Platycodon, was not documented in Asteraceae [44].

$P$. grandiflorum lacks five protein-coding genes: $a c c D$, clpP, infA, petE, and rpl23. Of these, accD, clpP, infA, and $r p l 23$ are also absent in the sequences of the four other Campanulaceae species we examined in this study.
A. remotiflora, C. takesimana, and $T$. caeruleum also lack petE, whereas $H$. asiatica has an intact petE gene. However, $H$. asiatica lacks $p s b E$, which is found in $P$. grandiflorum, A. remotiflora, C. takesimana, and T. caeruleum. C. takesimana, $H$. asiatica, A. remotiflora, and $T$. caeruleum lack ycf15, which is found in P. grandiflorum, whereas $T$. caeruleum lacks $n d h K$ and $y c f 2$. In addition to the presence/absence of these genes, there is variation in the number of copies of the genes among Campanulaceae species (Table 3). A conspicuous difference found between $P$. grandiflorum and the four other campanule species examined in the present study is variation in the number of copies of rps12 fragments. Among the 30 conserved trn genes, P. grandiflorum lacks trnT_ugu and A. remotiflora, C. takesimana, and $H$. asiatica lack trnT_ggu, whereas T. caeruleum has all 30 trn genes (Additional file 3: Table S3). As a minimal set of plastid trnA genes $[45,46]$ for trytophan, $P$. grandiflorum uses only trn $T$ ggu, whereas $A$. remotiflora, C. takesimana, and $H$. asiatica use only trnT_ugu. In contrast, $T$. caeruleum uses both trnT_ggu and trnT_ugu for trytophan in the plastid genome.

Angiosperm plastids generally contain one group I intron and 20 group II introns. The P. grandiflorum $\mathrm{cp}$ genome was found to contain 17 different introns, including 16 group II introns and one group I intron with a cyanobacterial origin [47] located within the trnL_uaa gene (Additional file 4: Table S4). Three protein-coding genes, clpP, rps12, and $y c f 3$, contain two group II introns (rps12.i1, rps12.i2, $y c f 3 . i 1$ and $y c f 3 . i 2$ ), and 14 genes contain a single group II intron: rpl2.i, rpl16.i, atpF.i, petB.i, petD.i, ndhA.i, ndhB.i, trnA_ugc.i, trnG_ucc.i, trnI_gau.i, trnK_uuu.i, and trn $V$ _uac.i. Of the 20 group II introns, the intron in rps12, 
Table 3 Plastid protein-coding gene distribution among Campanulaceae species

\begin{tabular}{|c|c|c|c|c|c|c|c|c|c|c|c|}
\hline & Platycodon & Hanabusaya & Trachelium & Campanula & Adenophora & & Platycodon & Hanabusaya & Trachelium & Campanula & Adenophora \\
\hline$\overline{a c c D}$ & - & - & $\psi \psi$ & - & - & psbH & + & + & + & + & + \\
\hline atpA & + & + & + & + & + & psbl & + & + & + & + & + \\
\hline$a t p B$ & + & + & + & + & + & psbJ & + & $++\psi$ & +++ & $++\psi$ & $++\psi$ \\
\hline atpE & + & + & + & + & + & psbK & + & + & + & + & + \\
\hline atpF & + & + & + & + & + & $p s b l$ & + & + & + & + & + \\
\hline atpH & + & + & + & + & + & psbM & + & + & + & + & + \\
\hline atpl & + & + & + & + & + & $p s b N$ & + & + & + & + & + \\
\hline $\operatorname{ccs} A$ & + & + & + & + & + & psbT & + & + & + & + & + \\
\hline cemA & + & + & + & + & + & psbZ & + & + & + & + & + \\
\hline$c l p P$ & $\psi$ & $\psi \psi$ & $\psi \psi$ & $\psi \psi$ & $\psi \psi$ & $r b c L$ & + & + & + & + & + \\
\hline $\operatorname{infA}$ & - & - & $\psi$ & $\psi$ & $\psi$ & rp/14 & ++ & + & + & + & + \\
\hline matK & + & + & + & + & + & $r p / 16$ & ++ & + & + & + & + \\
\hline$n d h A$ & ++ & ++ & ++ & ++ & ++ & $r p / 2$ & ++ & + & + & + & + \\
\hline$n d h B$ & ++ & $+{ }^{1}$ & + & + & $\psi$ & rp/20 & + & + & + & + & + \\
\hline$n d h c$ & + & + & + & + & + & $r p / 22$ & ++ & + & + & + & + \\
\hline$n d h D$ & + & + & + & + & + & $r p / 23$ & $\psi \psi \psi \psi$ & $\psi$ & $\psi$ & $\psi$ & $\psi$ \\
\hline$n d h E$ & $+\psi$ & + & $+\psi$ & $+\psi$ & $+\psi$ & rp/32 & + & + & + & + & + \\
\hline$n d h F$ & + & + & + & + & + & rp/33 & + & + & + & + & + \\
\hline$n d h G$ & ++ & ++ & ++ & ++ & ++ & rp/36 & ++ & + & + & + & + \\
\hline$n d h H$ & ++ & ++ & ++ & ++ & ++ & rpoA & + & + & + & + & + \\
\hline ndhl & ++ & ++ & + & ++ & ++ & $r p o B$ & + & + & + & + & + \\
\hline$n d h J$ & + & + & + & + & + & rpoCl & + & + & + & + & + \\
\hline$n d h K$ & + & + & $\psi$ & + & + & rpoc2 & + & + & + & + & + \\
\hline petA & + & + & + & + & + & rps11 & + & + & + & + & + \\
\hline petB & + & + & + & + & + & $5^{\prime}$ rps 12 & + & ++ & ++ & ++ & ++ \\
\hline petD & + & + & + & + & + & $3^{\prime} \operatorname{rps} 12$ & ++ & + & + & + & + \\
\hline petE & - & + & - & - & - & rps 14 & + & + & + & + & + \\
\hline petG & + & + & + & + & + & rps15 & ++ & ++ & ++ & ++ & ++ \\
\hline petL & + & + & + & + & + & rpsi6 & $+^{2}$ & + & + & + & + \\
\hline petN & + & + & + & + & + & rps 18 & + & + & + & + & + \\
\hline psaA & + & + & + & + & + & rps19 & ++ & + & + & + & + \\
\hline$p s a B$ & + & + & + & + & + & rps2 & + & + & + & + & + \\
\hline psac & + & + & + & + & + & rps3 & ++ & + & + & + & + \\
\hline psal & + & + & + & + & + & rps4 & + & + & + & + & + \\
\hline psal & + & + & + & + & + & rps7 & ++ & + & + & + & + \\
\hline$p s b A$ & + & + & + & + & + & rps8 & ++ & + & + & + & + \\
\hline$p s b B$ & + & $+\psi \psi$ & $+\psi \psi$ & $+\psi \psi$ & $+\psi \psi$ & ycf1 & ++ & ++ & + & ++ & ++ \\
\hline$p s b c$ & + & + & + & + & + & $y c f 2$ & ++ & + & $\psi$ & + & + \\
\hline$p s b D$ & + & + & + & + & + & ycf3 & + & $+\psi$ & $+\psi \psi$ & $+\psi \psi$ & $+\psi \psi$ \\
\hline$p s b E$ & + & - & + & + & + & $y c f 4$ & + & + & + & + & + \\
\hline$p s b F$ & + & + & + & + & + & ycf15 & ++ & - & $\psi$ & $\psi$ & - \\
\hline
\end{tabular}

' + ' indicates presence of the gene, ' $\psi$ ' indicates pseudo-copy of the gene, and ' - ' indicates complete absence of the gene. ' $\psi \Psi$ ' indicates two pseudo-copies of the gene $1,5^{\prime}$ end variation; 2 , GTG starting codon 
between exons 1 and 2, is trans-splicing, whereas the other 19 group II introns are cis-splicing.

Thirty genes, six introns, and parts of two genes and one intron are found within the IR, which has two copies. These 19 genes include seven protein-coding genes (ndhA, ndhB, ndhG, ndhH, ndhI, rpl2, rpl14, rpl16, rpl22, rpl36, rps3, rps7, rps8, rps12.e2, rps12.e3, rps15, rps19, $y c f 1, y c f 2$, and $y c f 15)$, all four rRNA genes (16S, $23 \mathrm{~S}, 4.5 \mathrm{~S}$, and $5 \mathrm{~S}$ ), and seven tRNA genes (trnA_ugc, trnI_cau, trnI_gau, trnL_caa, trnN_guu, trnR_acg, and $\left.\operatorname{trn} V \_g a u\right)$. The six introns are $n d h B . i, r p l 2 . i, \operatorname{trn} A \_u g c . i$, trnI_gau.i, rps12.i1t, and rps12.i2. The IR also contains the $5^{\prime}$ end of $n d h E$ at the border with the SSC region, resulting in one intact $n d h E$ and a 192 bp $\psi-n d h E$ in the cp genome. In addition, the IR contains parts of the rps12 gene. This rps12 gene consists of three exons, rps12.e1, rps12.e2, and rps12.e3 [48]. rps12.e1 is located in the LSC region, whereas rps12.e2 and rps12.e3 are located in the IR. Thus, the genome contains a single copy of rps12.e1 but has two copies of rps12.e2 and rps12.e3. A cis-splicing group II intron, rps12.i2, intervenes between rps12.e2 and rps12.e3, but a trans-splicing intron, rps12.i1t, occurs between rps12.e1 and rps12.e2. The rps12.i1t is split into two sections, rps12.i1t1 and rps12.i1t2. This is because the rps12 gene is transcribed in two separate operons, namely, the $\operatorname{clpP}$ operon ( $\psi$ clpP - rps12.e1 - rps12.i1t1 - rpl20) and the 3' rps12 operon (rps12.i1t2 - rps12.e2 - rps12.i2 - rps12.e3 - rps7$n d h B)$. P. grandiflorum contains the $3^{\prime}$ rps12 operon (rps12.i1t2 - rps12.e2 - rps12.i2 - rps12.e3 - rps7 - ndhB) within the IR.

The complete cp genomes of $P$. grandiflorum, C. takesimana, $H$. asiatica, and T. caeruleum of Campanulaceae and Helianthus annuus of Asteraceae were compared using the MAUVE alignment tool. Inverted Repeat B of the five chloroplasts was deleted prior to the MAUVE alignment, such that the genome-level alignments could be maximally shown (Fig. 2). In Fig. 2, the thick black bar indicates the IR region of each species. Helianthus has a typical asterid chloroplast genomic structure. A comparison of the cp-DNAs of Helianthus and Platycodon shows the expansion of the IR toward both LSC and SSC in Platycodon (Fig. 2 and Table 2), whereas comparison among the campanule cp-genomes shows disruption of the IR and LSC by severe rearrangement.

The region between the $\mathrm{LSC}$ region and the IR of angiosperm plastid genomes is generally conserved: $5^{\prime}$ (clpP operon) - psbB operon [49] - (rpl23 operon) - ycf2 - ycf15 - trnV_gac - (3' rps12 operon) - 3' (Fig. 2). In contrast to Helianthus, the clpP operon (A) of the LSC region has relocated to the middle of the $\mathrm{LSC}$ region in $P$. grandiflorum. However, the clpP operon (A) has relocated within the IR in the cp-DNA of $A$. remotiflora, $C$. takesimana, $H$. asiatica, and T. caeruleum. In these four taxa, fragments B, D (3' rps12 operon), E, and F have relocated in the middle of the LSC region.

The rpl23 gene cluster containing 13 genes (trnI_cau rpl23 - rpl2* - rps19 - rpl22 - rps3 - rpl16* rpl14 - rps8 infA - rpl36 - rps11 - rpoA) (Fig. 3) is conserved from the charophyte Spirogyra [48, 50], bryophytes [51], ferns [52], and gymnosperms [53] to eudicots. P. grandiflorum has lost rpl23 and infA. In A. remotiflora, C. takesimana, $H$. asiatica, and T. caeruleum, trnI_cau has been relocated in the LSC region, separate from the rpl23 gene cluster. The clpP operon (clpP $P^{* *}$ - rps12.e1 - rps12.i1t1 - rpl20) is conserved from bryophytes [51], ferns [52], and gymnosperms [53] to eudicots. P. grandiflorum carries $\psi$-clpP - rps12.e1 - rps12.i1t1 - rpl20. A. remotiflora, C. takesimana, H. asiatica, and T. caeruleum harbor a member of the clpP operon divided by genomic rearrangement into two separated fragments, rps12.e1 - rps12.i1t1 and rpl20. The structure of the (trn $\left.V \_g a c\right)$ - 3' rps12 operon in the IR is conserved from Spirogyra [48], bryophytes [51], ferns [52], gymnosperms [53], and eudicots to P. grandiflorum. A. remotiflora, $C$. takesimana, $H$. asiatica, and $T$. caeruleum exhibit the members of this structure divided into two separated fragments, trn $V \_g a c$ and the $3^{\prime}$ rps 12 operon in the LSC region. The results indicate that the cp-DNA of A. remotiflora, C. takesimana, $H$. asiatica, and $T$. caeruleum is somewhat derived compared with that of $P$. grandiflorum.

The duplicative nature of the IR reduces the substitution rate within this region. As the most illustrative single example of the effect of IR duplication on substitution rates, Zhu et al. [13] demonstrated that, consistent with other comparisons, the SC-to-IR genes in Hanabusaya and Trachelium show IR-like substitution rates, whereas their IRto-SC genes show SC-like substitution rates. However, in the case of Platycodon, the SC-to-IR genes have been generated by a border shift, rather than genomic rearrangement, as shown in other campanules.

\section{Nr-acc $D$ of $P$. grandiflorum}

A 1282 bp segment of $n r-a c c D$ mRNA containing a 996 bp exon was recovered from RNA seq reads. The sequence was verified via RT-PCR, followed by sequencing. Genomic DNA sequences for $n r-a c c D$ with lengths of $225 \mathrm{bp}$ and $1464 \mathrm{bp}$ were recovered from DNA-seq reads, referenced according to the $1282 \mathrm{bp}$ mRNA sequence. We recovered a $4.1 \mathrm{~kb}$ sequence of the genomic $n r-a c c \mathrm{D}$ gene fragment. The cDNA and DNA sequences of $P$. grandiflorum $\mathrm{nr}-a c c D$ were compared with the previously reported $n r-a c c D$ gene and intron sequences of T. caeruleum (JQ693029), Jasione perennis (JQ693031), Campanula thyrsoides (JQ693032), and Campanula punctate (JQ693033) [33]. The intron of $n r-a c c D$ in $P$. grandiflorum has the same insertion site as observed in these other species (Fig. 4). About $3.2 \mathrm{~kb}$ intron of $P$. 


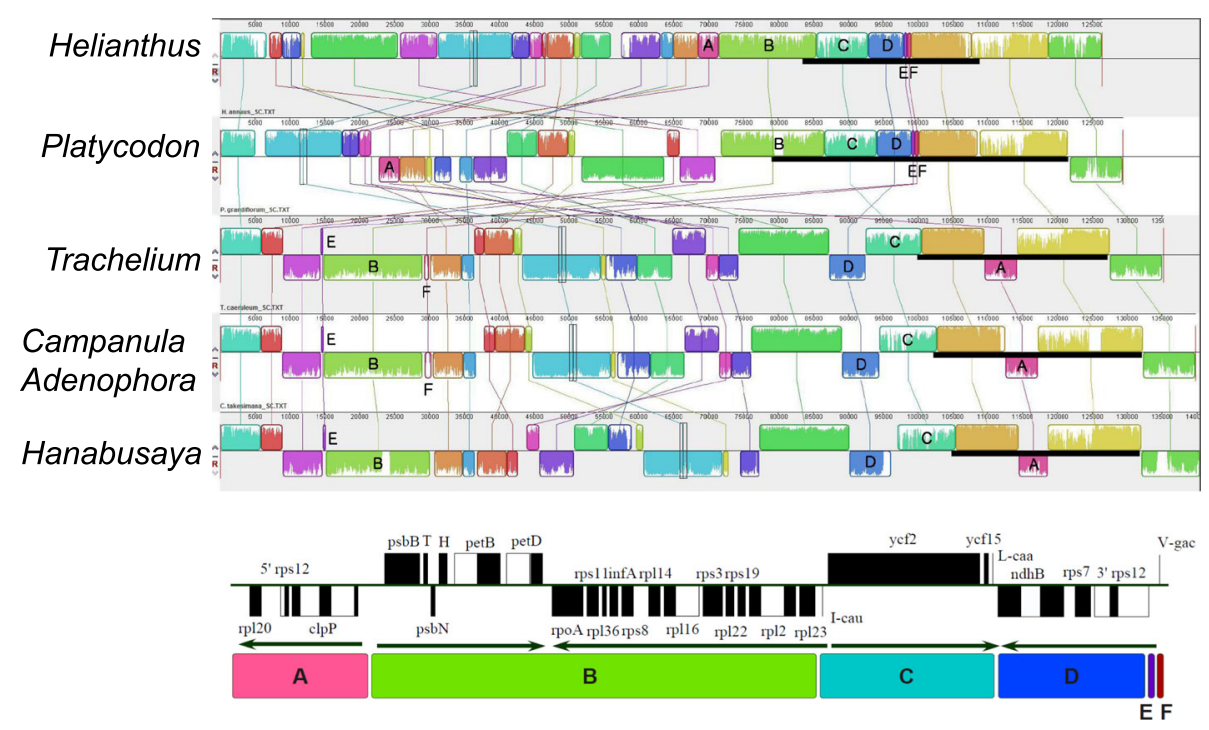

Fig. 2 Comparison of the chloroplast genomes of Helianthus of Asteraceae and Platycodon, Trachelium, Adenophora, Campanula, and Hanabusaya of Campanulaceae. In this analysis, Inverted Repeat B was removed for convenience. A conserved region was found at the junction between the large single-copy (LSC) region and the IR of the angiosperm plastid genome, but it was rearranged in the Campanulaceae plastids. The thick black bar indicates the IR region of each species. Regions are marked in six parts, a-f. a: $c l p P$ operon ( - strand); b: psbB operon (+ strand) - rpl23 operon (+ strand); c: ycf2 - ycf15 - trnL_caa (+ strand); D: 3' rps12 operon (- strand); e: Intergenic spacer between 3' rps12 and trnV_gac genes; f: trnV_gac gene $(+$ strand)

grandiflorum nr-accD (Additional file 5: Figure S1) appears to be the largest among the taxa examined to date: Jasione perennis (2250 bp), T. caeruleum (1358 bp), Campanula thyrsoides (2177 bp), and Campanula punctate (2431 bp). These results indicate that the campanule $\mathrm{nr}-a c c D$ and its intron share a common ancestor.

\section{Phylogeny of plastids and $a c c D$ genes among Campanulaceae species}

Phylogenetic relationships among the plastids of four Campanulaceae species were investigated using the aligned 10,950 bp DNA sequence of seven large photosystem genes - $p s a A, p s a B, p s b A, p s b B, p s b C$, and $p s b D$,

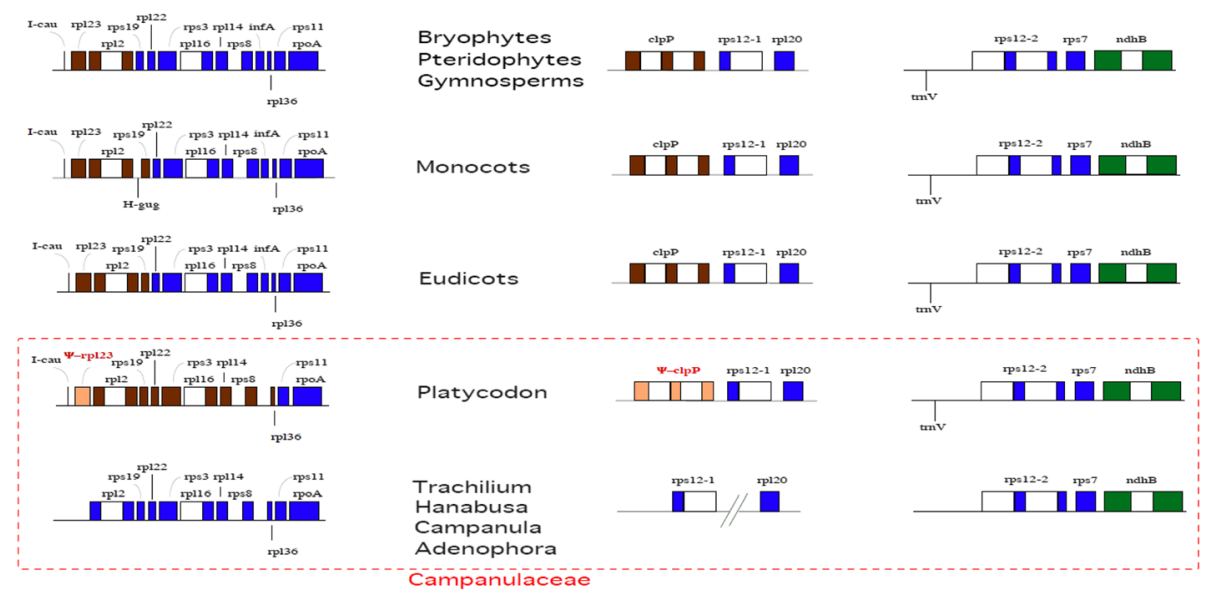

Fig. 3 Comparison of the rpl23, clpP, and 3' rps 12 gene clusters in land plant plastids. Genes shown on the upper part are encoded on the + strand and genes shown on the lower part are encoded on the - strand. Closed boxes indicate exons and open boxes indicate introns. The left column shows the rpl23 operon. The dark brown color indicates inverted repeats (IR) and blue color indicates the large single-copy region (LSC). The middle column shows the clpP operon. Platycodon has an clpP operon structure with a trace of exons and introns. Other known Campanulaceae species have lost the IpP operon structure by genomic rearrangement. The right column shows the 3' rps 12 operon. trnV_gac precedes the 3' rps 12 operon in Platycodon and most land plants, but other known Campanulaceae species have lost this arrangement 


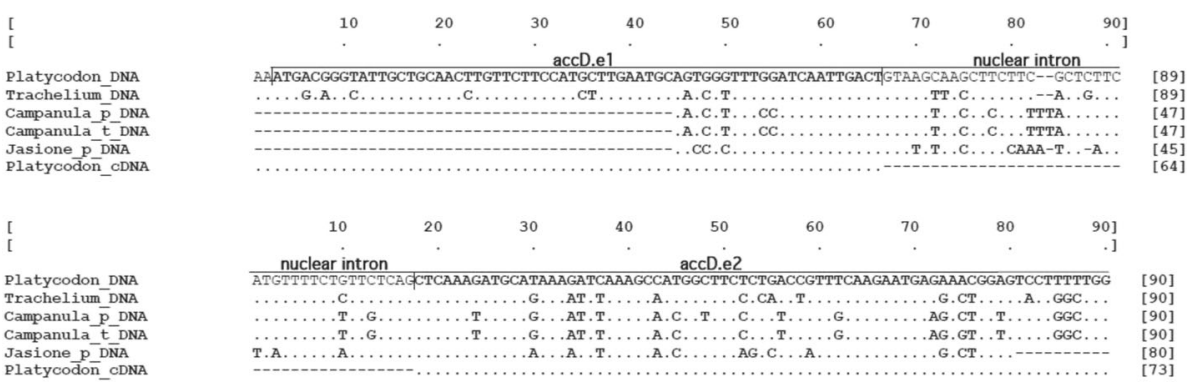

Fig. 4 Border sequences between the nr- $a c c D$ exons and introns in Campanulaceae species. The nr-accD of Campanulaceae contains a nuclear intron. The first row shows the aligned border of the $a c c D . e 1$ and $a c c D$ introns and the second row shows the aligned border of accD and $a c c D . e 2$ introns.

The dot indicates the same sequence of the first line sequence and ' - ' indicates absence of the sequence or gap

and $r b c L$. The seven genes representing the plastid genome in the phylogeny [43] are without RNA editing, which might affect phylogenetic topology. Using maximum parsimonious (MP), and neighbor-joining (NJ), and maximum likelihood (ML) methodologies, phylogenetic analysis outgrouped by 13 taxa produced single plastid trees with similar topologies (Additional file 6: Figure S2). The plastid phylogeny showed that $P$. grandiflorum is the most basal of the clade of Campanulaceae species (Fig. 5).
Phylogenetic relationships among 11 Campanulaceae $\mathrm{nr}-a c c D$ genes were investigated using the aligned $616 \mathrm{bp}$ DNA and RNA sequences. Using MP, NJ, and ML analyses, phylogenetic analysis outgrouped by $\mathrm{cp}-a c c D$ sequences from 13 taxa produced single plastid trees with similar topologies (Additional file 7: Figure S3). The $a c c D$ phylogeny showed that $P$. grandiflorum and Lobelia erinus formed the basal-most clade from the lineage of nine taxa (Fig. 5). The results of both phylogenies indicate that $P$. grandiflorum is a basal lineage of Campanulaceae.

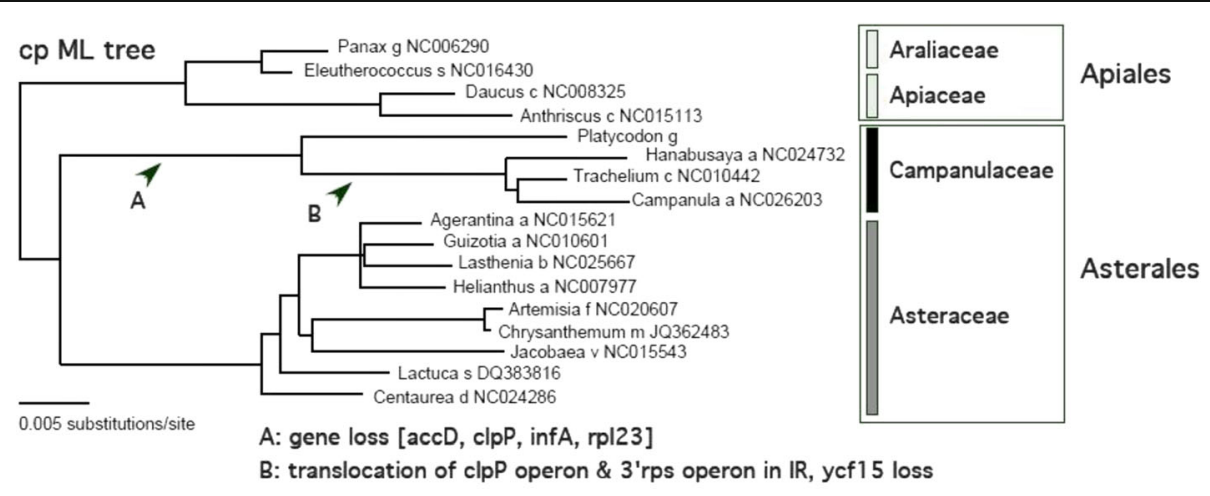

accD ML tree

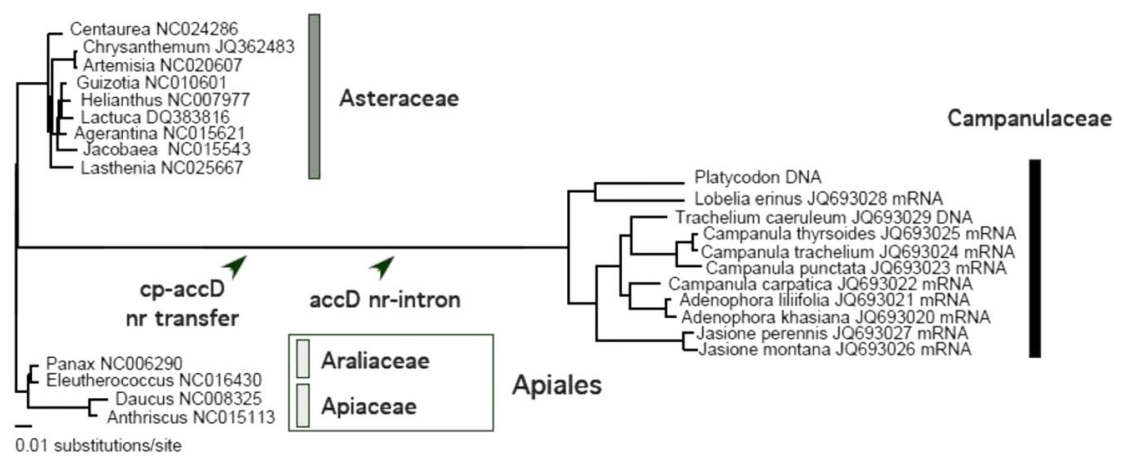

Fig. 5 Single maximum-likelihood (ML) trees of plastid genes and the accD gene. A: Single ML (HYK85 + G + I model) tree based on the DNA sequences of seven cp genes (six photosystem genes and rbcL). A: Single ML (HYK85 $+G+I$ model) tree based on the DNA and RNA sequence of nr-accD gene and cp-accD gene 
The evolution of $a c c D$ and cpDNA in Campanulaceae Phylogenetic study of $n r-a c c D$ and $c p-a c c D$ (Fig. 5) indicates that the $n r-a c c D$ of Campanulaceae is of single origin. The $c p-a c c D$ was transferred to the nucleus in the early campanules and later a nuclear intron was introduced. The phylogeny of cpDNA indicates that IR expansion and the loss of four cp-genes (accD, clpP, infA, and rpl23), represented by Platycodon cp-DNA, had occurred in the early campanule plastid genome, followed by the translocation of the $\operatorname{clpP}$ and 3' rps12 operons between the LSC and IR regions. The evolution of an IR with 30 genes would have slowed down the evolutionary speed in the early campanule. In this regard, further characterization of basal campanules, including Lobeliaceae, would enable us to gain a better understanding of $\mathrm{cp}$-genome evolution.

Among embryophytes, in $80 \%$ of the cases where $y c f 1$ was lost from the plastid genome, there was a concomitant loss of accD [54, 55]. In Odontella purpurea, Erodium of Generaniaceae and Vaccinium macrocarpon of Ericaceae, $a c c D$ is still present in the chloroplast genome, although it does not encode a YCF1 homolog [55]. All five campanules investigated in the present study, including Platycodon, lack cp-accD and the complete $y c f 1$ gene is within the IR, in which synonymous substitution rates are, on average, 3.7 times slower than those in SC genes [13]. The substitution rate of $a c c D$ and $y c f 1$, both of which are located in the SC region of most angiosperms, is high [55, 56]. The results may indicate that YCF1 is involved in the assembly of the ACCase holoenzyme [55].

\section{Conclusions}

In this study, we characterized the 171,818 bp cp genome of $P$. grandiflorum, the largest among known Campanulaceae species. This genome contains 110 genes and 18 introns, among which there are 77 protein-coding genes, four RNA genes, 29 tRNA genes, 17 group II introns, and one group I intron. RNA editing of genes was detected in 18 sites of 14 genes. P. grandiflorum cpDNA lacks five protein-coding genes, namely, accD, $c l p P$, infA, petE, and rpl23. Of these, we characterized nraccD. Platycodon $\mathrm{nr}-a c c D$ contains about $3.2 \mathrm{~kb}$ intron between nr-accD.e1 (64 bp) and nr-accD.e2 (932 bp) at the same insertion position as in other Campanulaceae. Unlike the highly rearranged cp-DNAs of $A$. remotiflora, C. takesimana, $H$. asiatica, and T. caeruleum, P. grandiflorum cp-DNA contains the $5^{\prime}-p s b B$ operon - $(r p l 23$ operon) - ycf2 - ycf15 - trn $V \_g a c$ - (3' rps12 operon) $3^{\prime}$, which is conserved in most land plant plastid genomes. Phylogenetic studies of $\mathrm{cp}$ genes and $a c c D$ genes support the hypothesis that $P$. grandiflorum belongs to the basal lineage of Campanulaceae.

Our phylogenetic studies also support the notion that severe genomic rearrangements occurred in the chloroplast genome after $a c c D$ nuclear transfer and the loss of four genes in early Campanulaceae as a lineage of asterids. $a c c D, \operatorname{clpP}$, infA, and $r p l 23$ are also absent in all three known Campanulaceae species. The loss of these four genes in the cp genome appears to be a shared derived characteristic in Campanulaceae. Further survey of the cp genomes of Campanulaceae and their close relatives will provide a better understanding of the nuclear transfer of the members of $\mathrm{cp}$ genomes.

\section{Methods \\ Plant materials and nucleotide extraction}

P. grandiflorum cultivar Jangbaek-doraji was grown for 1 year in a bellflower field in the Department of Herbal Crop Research, RDA, Eumseong, Korea. Collected samples were divided into leaves, stems, roots, petals, sepals, pistils, stamens, and seeds. To extract total RNA, each sample was frozen in liquid nitrogen and ground using a mortar and pestle. Total DNA was extracted using a DNeasy Plant Mini Kit (Qiagen, USA), and total RNA for cDNA library construction was extracted using an RNeasy Plant Mini Kit (Qiagen, USA) according to the manufacturer's instructions.

\section{Sequencing, assembly, and annotation of the Platycodon plastid genome}

The plastid genome of $P$. grandiflorum cultivar Jangbaekdoraji was sequenced as part of the Jangbaek-doraji genome project (funded by the National Agricultural Genome Center). Three Illumina paired-end (PE) genomic libraries of 270,500 , and $700 \mathrm{bp}$ were constructed and sequenced using an Illumina HiSeq 2000 platform. The plastid sequence was obtained using CLC Genomics Workbench version 8.0. The circular structures of each replicon were confirmed by polymerase chain reaction (PCR) amplification at their ends and by joining of Sanger sequence reads derived from the amplicons. The assemblies were further verified by examining paired-end distance and depth after re-mapping reads on the contig sequences. BLAST searches of a large contig were verified to be plastid genomes. For gene annotation of organelle genomes, protein-coding and ribosomal RNA genes were annotated using DOGMA (http://dogma.ccbb.utexas.edu/) [57]. The boundaries of each annotated gene were manually determined by comparison with orthologous genes from other known cp genomes. Genes encoding tRNAs were initially predicted using tRNAscan (http://lowelab.ucsc.edu/ tRNAscan-SE) [58] and ARAGORN version 1.2 (http:// 130.235.46.10/ARAGORN/) [59], and were then manually verified by predicting the tRNA secondary structure. Circular genome maps were drawn using GenomeVx [60], followed by manual modification. The sequencing data and gene annotations were submitted to GenBank with accession number KX352464. 
RNA sequencing and RNA editing site tracing from the plastid genome

The quality of the resulting total RNA was measured using an Agilent 2100 Bioanalyzer (Agilent Technologies, Santa Clara, CA). All extractions delivered an RNA integrity number value (RIN) of $>7.0$ and a $28 \mathrm{~S}: 18 \mathrm{~S}$ ratio $\geq 1.5$.

Poly-A-containing mRNA molecules were purified from $2 \mu \mathrm{g}$ of total RNA of each sample using poly-T oligo-attached magnetic beads. The mRNA was fragmented into an insert size of approximately $200 \mathrm{bp}$. The first-strand cDNA of the mRNA fragments was synthesized using reverse transcriptase and random hexamer primers. The second-strand cDNA was then synthesized using DNA Polymerase I and RNaseH to generate double-stranded cDNA. These cDNA fragments then went through an end repair process, the addition of a single "A" base, and ligation of adapters. The products were then purified and enriched by PCR to amplify the amount of DNA in the library. The libraries were quantified using a KAPA library quantification kit (KAPA Biosystems, South Africa) in an Agilent 2100 Bioanalyzer (Agilent Technologies, Waldbronn, Germany). After qPCR validation, libraries were subjected to paired-end sequencing with a $100 \mathrm{bp}$ read length using the Illumina HiSeq 2500 platform (Illumina). After the completion of a sequencing run, raw image files were processed using Illumina Real-Time Analysis (RTA) for image analysis and base calling. Raw data were saved as FASTQ files. Clean reads were obtained by removing adaptor sequences, reads in which the percentage of unknown bases $(\mathrm{N})$ was greater than $10 \%$, and low-quality reads (more than $20 \%<\mathrm{Q} 20$ bases). The high-quality reads were directly mapped to the plastid genome to trace RNA editing sites.

mRNA sequencing, cDNA synthesis, RT-PCR, and DNA-PCR for $n r-a c c D$

The RNA-seq analysis results were analyzed using CLC Genomics Workbench 8.0 (CLC bio, Denmark). The adapter sequences contained in the data were removed using the trim sequence program and remaining sequences were assembled into contigs by de novo assembly. The plastid $a c c D$ of Helianthus was used to find the nr-accD of $P$. grandiflorum using an Xblast search. A 1282 bp RNA seq containing a 1020 bp nr-accD was found. cDNA was synthesized from $1 \mu \mathrm{g}$ of total RNA, which was extracted from a $P$. grandiflorum leaf using Plant TRI reagent (Invitrogen, USA). cDNA was synthesized using an iScriptTM cDNA Synthesis Kit (Bio-Rad, USA) and a 2720 Thermal Cycler (Applied Biosystems, USA) according to the manufacturers' instructions. PCR amplification of the $a c c D$ gene was carried out using the HS PrimeSTAR Component Mixture (Takara, Japan). The PCR reaction consisted of a total of $50 \mu \mathrm{L}(10 \mu \mathrm{L}$ of
$5 \times$ HS buffer, $1 \mu \mathrm{L}$ of forward and reverse primers (10 $\mu \mathrm{M}$, Forward; 5' -GAGAGAAATGACGGGTATTG C-3', Reverse; 5'-CTCCCACTCAAAATGTTTTAC-3'), $5.0 \mu \mathrm{L}$ of dNTP, $1.0 \mu \mathrm{L}$ of template, 2.5 units of PrimeSTAR polymerase, and made to volume with distilled water). The amplification program was as follows: preheating at $98{ }^{\circ} \mathrm{C}$ for $1 \mathrm{~min}$, followed by 28 cycles of denaturation at $98{ }^{\circ} \mathrm{C}$ for $10 \mathrm{~s}$, annealing at $58{ }^{\circ} \mathrm{C}$ for $30 \mathrm{~s}$, and extension at $72{ }^{\circ} \mathrm{C}$ for $1 \mathrm{~min}$ and $30 \mathrm{~s}$, and a final extension at $72{ }^{\circ} \mathrm{C}$ for $5 \mathrm{~min}$. The $1240 \mathrm{bp}$ PCR product was purified using a Biomedical Gel and PCR Purification Kit (Biomedic, Korea) and sequenced using a 3730 DNA Analyzer (Applied Biosystems, USA).

Genomic DNA sequences of $n r-a c c D$ with lengths of 225 bp and 1464 bp were recovered by mapping DNA reads to the 1282 bp RNA sequence using CLC Genomics Workbench version 8.0. A $4.2 \mathrm{~kb}$ genomic accD gene fragment was recovered using LA Taq (Takara, Japan), and two long primer sets: accD_PL_LPRF (5'-GGTA TTGCTGCAACTTGTTCTTCCATGC-3') and $a c c D \_P L$ LPR (5' -TCTCGAACAAATACTCGGCCTGTTGTACGC -3'); accD_PL_LPRF1 (5' - ACTTGTTCTTCCATGCTTG AATGCAGTGG-3') and $a c c D \_P L \_L P R 1$ (5' - CCAGCAT AGCGAAACTAGCTGTCACCCCTC-3'). The RNA sequence for $\mathrm{nr}-a c c D$, two DNA sequences containing nr$a c c D . e 1, \mathrm{nr}-a c c D . e 2$, and partial sequences of the $\mathrm{nr}-a c c D$ intron were submitted to GenBank with the accession numbers KX352462 and KX352463. The cDNA and DNA sequences of $P$. grandiflorum nr-accD were compared with the previously reported $\mathrm{nr}-a c c D$ gene and intron DNA sequences of $T$. caeruleum (JQ693029), Jasione perennis (JQ693031), Campanula thyrsoides (JQ693032), and Campanula punctate (JQ693033) [27].

\section{Comparative analysis of $\mathrm{cp}$ genomes}

The complete cp genomes of $P$. grandiflorum, C. takesimana, $H$. asiatica, and T. caeruleum of Campanulaceae and Helianthus annuus of Asteraceae were compared using the MAUVE alignment tool [61] to identify rearrangement-free locally collinear blocks (LCBs) among genomes, yielding 25 LCBs with a minimum weight of 170. Inverted repeat A of the five chloroplasts was deleted prior to the MAUVE alignment so that the genome-level alignments could be maximally shown.

\section{Phylogenetic analysis}

The phylogenetic relationships of Campanulaceae in Asterales were investigated using the chloroplast genomic information. Reported Campanulaceae plastid genomic information for $H$. asiatica (NC024732), C. takesimana (NC026203), and T. caeruleum (NC010442) was included as an ingroup. To avoid bias by taxon sampling, nine Asteraceae, two Apiaceae, and two Araliaceae were used as an outgroup. These included Agerantina (NC015621), 
Guizotia (NC010601), Helianthus (NC007977), Lasthenia (NC025667), Artemisia (NC020607), Chrysanthemum (JQ362483), Jacobaea (NC015543), Lactuca (DQ383816), and Centaurea (NC024286) of Asteraceae; Daucus (NC008325) and Anthriscus (NC015113) of Apiaceae; and Panax (NC006290) and Eleutherococcus (NC016430) of Araliaceae. DNA sequences of seven cp protein genes, $p s a A, p s a B, p s b A, p s b B, p s b C, p s b D$, and $r b c L$, were used to construct cp phylogenetic trees by MP, NJ, and ML analyses using Paup ver. 6.0 [62]. In addition, the phylogenetic relationships of $a c c D$ were investigated. cp- $a c c D$ sequences from 13 taxa were used as an outgroup, and all reported Campanulaceae nr-accD RNA and DNA sequences were included as an ingroup. These included the sequences of Lobelia erinus (JQ693028), T. caeruleum (JQ693029), Campanula thyrsoides (JQ693025), Campanula trachelium (JQ693024), Campanula punctata (JQ693023), Campanula carpatica (JQ693022), Adenophora liliifolia (JQ693021), Adenophora khasiana (JQ693020), Jasione perennis (JQ693027), and Jasione montana (JQ693026) [33].

\section{Additional files}

Additional file 1: Table S1. Gene contents of the Platycodon grandiflorum plastid. (DOCX $25 \mathrm{~kb}$ )

Additional file 2: Table S2. Cytidine $(C)$ to uridine $(U)$ editing sites in the chloroplast genome of Platycodon validated by RNA-Seq data from leaf, root, stem, seed, petal, pistil, sepal, and stamen. (DOCX 21 kb)

Additional file 3: Table S3. Plastid tRNA and rRNA gene distribution among Campanulaceae species. ' + ' indicates presence of the gene, and ' - ' indicates complete absence of the gene. ' $\psi \psi$ ' indicates two pseudocopies of the gene. The number of ' + ' indicates the copy number of the gene. (DOCX $16 \mathrm{~kb}$ )

Additional file 4: Table S4. Plastid intron distribution in Campanulaceae species and other related taxa. ' + ' indicates presence of the gene, ' $\Psi$ ' marks pseudo-copy of the gene, and '-' indicates complete absence of the gene. $' \psi \psi \psi^{\prime}$ indicates two pseudo-copies of the gene. (DOCX $18 \mathrm{~kb}$ )

Additional file 5: Figure S1. CDNA and DNA PCR confirmation of nr-accD in Platycodon grandiflorum. A: The size of the $\mathrm{nr}-a c c D$ cDNA sequence, primer sites, and CDNA PCR products in P. grandiflorum cultivars. B: The size of the $n r-a c c D$ DNA sequence, primer sites, and genomic DNA PCR products in $P$. grandiflorum cultivars. PL03 [accD_PL_LPRF accD_PL_LPR] and PL05 $[a c c D$ PL_LPRF1 $\sim$ accD_PL_LPR1]. (PPTX $757 \mathrm{~kb}$ )

Additional file 6: Figure S2. Phylogenetic trees generated from the DNA sequences of seven cp-genes using three algorithms. (A) single maximum parsimonious (MP) tree, (B) single neighbor-joining (NJ) tree, and $(C)$ single maximum likelihood $(\mathrm{ML})$ tree (HYK85 + G + I model). (PPTX $749 \mathrm{~kb}$ )

Additional file 7: Figure S3. Phylogenetic trees generated from the DNA sequences of the $a c c D$ gene using three algorithms. (A) single maximum parsimonious (MP) tree, (B) single neighbor-joining (NJ) tree, and $(C)$ single maximum likelihood $(\mathrm{ML})$ tree (HYK85 + G + I model). (PPTX $857 \mathrm{~kb}$ )

\section{Abbreviations}

3' rps12 operon: rps12.i1t2 - rps12.e2 - rps12.i2 - rps12.e3 - rps7; clpP**: clpP having two introns; cp: Chloroplast; IRs: Inverted repeats; LSC: Large single-copy region; nr: Nuclear; rp/2*: rp/2 having an intron; rpl2.i: An intron in rpl2; rps 12.e1: Exon 1 of rps 12; rps 12.i1t: Trans-spliced first intron in rps 12; rps 12.i1t1: 5' end sequence of trans-spliced first intron in rps 12; rps 12.i1t2: $3^{\prime}$ end sequence of trans-spliced first intron in rps 12; rps 12.i2: The second intron of rps 12; SSC: Small single-copy region

\section{Acknowledgments}

The authors would like to thank Dr. Ok Tae Kim, the Department of Herbal Crop Research, Rural Development Administration, for allowing the use of the plant material and RNA raw data in this study.

\section{Funding}

This work was supported by grants from the National Agricultural Genome Center (project No. PJ010351 \& PJ010456), Rural Development Administration, Republic of Korea.

\section{Availability of data and materials}

The complete chloroplast sequence of $P$. grandiflorum has been made freely available under accession KX352462 at NCBI GenBank. The RNA sequence of nr-accD, two DNA sequences containing nr-accD.e1 and nr-accD.e2, and partial sequences of the $n r-a c c D$ intron were submitted to GenBank with accession numbers: KX352462 and KX352463.

\section{Authors' contributions}

$J \mathrm{~L}, \mathrm{CPH}$, and C-KK designed the research and wrote the paper. $\mathrm{CPH}, J \mathrm{P}, \mathrm{YL}$, $\mathrm{ML}$, SGP, and $\mathrm{YU}$ performed the research. All authors read and approved the manuscript.

\section{Ethics approval and consent to participate}

Permission was obtained to collect and use the samples described in this study.

Consent for publication

Not applicable.

\section{Competing interests}

The authors declare that they have no competing interests.

\section{Publisher's Note}

Springer Nature remains neutral with regard to jurisdictional claims in published maps and institutional affiliations.

\section{Author details}

${ }^{1}$ Bioinformatics Team, Theragen Etex Bio Institute, Suwon 443-270, South Korea. ${ }^{2}$ Green Plant Institute, B-301, Heungdeok IT Valley, Giheung-gu, Yongin 446-908, South Korea. ${ }^{3}$ Department of Industrial Plant Science and Technology, Chungbuk National University, Cheongju 362-763, South Korea. ${ }^{4} \mathrm{Herbal}$ Crop Research Division, National Institute of Horticultural and Herbal Science (NIHH), RDA, Eumseong 369-873, South Korea. ${ }^{5}$ Genomics Division, National Institute of Agricultural Science (NAS), RDA, Jeonju 560-500, South Korea

Received: 1 July 2016 Accepted: 3 August 2017

Published online: 11 August 2017

\section{References}

1. Kolodner R, Tewari KK. Inverted repeats in chloroplast DNA from higher plants. Proc Natl Acad Sci U S A. 1979;76(1):41-5.

2. Lilly JW, Havey MJ, Jackson SA, Jiang J. Cytogenomic analyses reveal the structural plasticity of the chloroplast genome in higher plants. Plant Cell. 2001;13(2):245-54

3. Bendich AJ. Circular chloroplast chromosomes: the grand illusion. Plant Cell. 2004;16(7):1661-6.

4. Oldenburg DJ, Bendich AJ. Changes in the structure of DNA molecules and the amount of DNA per plastid during chloroplast development in maize. J Mol Biol. 2004;344(5):1311-30.

5. Oldenburg DJ, Bendich AJ. Most chloroplast DNA of maize seedlings in linear molecules with defined ends and branched forms. J Mol Biol. 2004; 335(4):953-70

6. Shaver JM, Oldenburg DJ, Bendich AJ. Changes in chloroplast DNA during development in tobacco, Medicago Truncatula, pea, and maize. Planta. 2006;224(1):72-82 
7. Shaver JM, Oldenburg DJ, Bendich AJ. The structure of chloroplast DNA molecules and the effects of light on the amount of chloroplast DNA during development in Medicago Truncatula. Plant Physiol. 2008;146(3):1064-74.

8. Palmer JD, Osorio B, Aldrich J, Thompson WF. Chloroplast DNA evolution among legumes: loss of a large inverted repeat occurred prior to other sequence rearrangements. Curr Genet. 1987;11:275-86.

9. Tsudzuki J, Nakashima K, Tsudzuki T, Hiratsuka J, Shibata M, Wakasugi T, Sugiura M. Chloroplast DNA of black pine retains a residual inverted repeat lacking rRNA genes: nucleotide sequences of trnQ, trnK, psbA, trnl and trnH and the absence of rps16. Mol Gen Genet. 1992;232(2):206-14.

10. Guisinger MM, Kuehl JV, Boore $J$, Jansen RK. Extreme reconfiguration of plastid genomes in the angiosperm family Geraniaceae: rearrangements, repeats, and codon usage. Mol Biol Evol. 2011;28(1):583-600.

11. Wu CS, Lin CP, Hsu CY, Wang RJ, Chaw SM. Comparative chloroplast genomes of pinaceae: insights into the mechanism of diversified genomic organizations. Genome biology and evolution. 2011;3:309-19.

12. Guo W, Grewe F, Cobo-Clark A, Fan W, Duan Z, Adams RP, Schwarzbach AE, Mower JP. Predominant and substoichiometric isomers of the plastid genome coexist within Juniperus plants and have shifted multiple times during cupressophyte evolution. Genome biology and evolution. 2014;6(3):580-90.

13. Zhu A, Guo W, Gupta S, Fan W, Mower JP. Evolutionary dynamics of the plastid inverted repeat: the effects of expansion, contraction, and loss on substitution rates. The New phytologist. 2016;209(4):1747-56.

14. Cosner ME, Jansen RK, Palmer JD, Downie SR. The highly rearranged chloroplast genome of Trachelium caeruleum (Campanulaceae): multiple inversions, inverted repeat expansion and contraction, transposition, insertions/ deletions, and several repeat families. Curr Genet. 1997;31(5):419-29.

15. Haberle RC. Phylogeny and comparative chloroplast genomics of the Campanulaceae. Austin: The University of Texas; 2006.

16. Haberle RC, Fourcade HM, Boore JL, Jansen RK. Extensive rearrangements in the chloroplast genome of Trachelium caeruleum are associated with repeats and tRNA genes. J Mol Evol. 2008:66(4):350-61.

17. Chumley TW, Palmer JD, Mower JP, Fourcade HM, Calie PJ, Boore JL, Jansen RK. The complete chloroplast genome sequence of pelargonium $\mathrm{x}$ hortorum: organization and evolution of the largest and most highly rearranged chloroplast genome of land plants. Mol Biol Evol. 2006;23(11):2175-90.

18. Cai Z, Guisinger M, Kim HG, Ruck E, Blazier JC, McMurtry V, Kuehl JV, Boore J, Jansen RK. Extensive reorganization of the plastid genome of Trifolium Subterraneum (Fabaceae) is associated with numerous repeated sequences and novel DNA insertions. J Mol Evol. 2008;67(6):696-704.

19. Milligan BG, Hampton JN, Palmer JD. Dispersed repeats and structural reorganization in subclover chloroplast DNA. Mol Biol Evol. 1989;6(4):355-68.

20. Palmer JD, Osorio B, Thompson WF. Evolutionary significance of inversion in legume chloroplast DNAs. Curr Genet. 1988;14:65-74.

21. Perry AS, Brennan S, Murphy DJ, Kavanagh TA, Wolfe KH. Evolutionary reorganisation of a large operon in adzuki bean chloroplast DNA caused by inverted repeat movement. DNA Res. 2002;9(5):157-62.

22. Jansen RK, Ruhlman TA. Plastid genomes of seed plants. In: Bock R, Knoop $\checkmark$, editors. Genomics of chloroplasts and mitochondria. New York: Springer; 2012. p. 103-26

23. Jansen RK, Cai Z, Raubeson LA, Daniell H, Depamphilis CW, Leebens-Mack J, Muller KF, Guisinger-Bellian M, Haberle RC, Hansen AK, et al. Analysis of 81 genes from 64 plastid genomes resolves relationships in angiosperms and identifies genome-scale evolutionary patterns. Proc Natl Acad Sci U S A. 2007:104(49):19369-74.

24. Magee AM, Aspinall S, Rice DW, Cusack BP, Semon M, Perry AS, Stefanovic S, Milbourne D, Barth S, Palmer JD, et al. Localized hypermutation and associated gene losses in legume chloroplast genomes. Genome Res. 2010;20(12):1700-10.

25. Matsuo M, Ito Y, Yamauchi R, Obokata J. The rice nuclear genome continuously integrates, shuffles, and eliminates the chloroplast genome to cause chloroplast-nuclear DNA flux. Plant Cell. 2005;17(3):665-75.

26. Noutsos C, Richly E, Leister D. Generation and evolutionary fate of insertions of organelle DNA in the nuclear genomes of flowering plants. Genome Res. 2005:15(5):616-28

27. Timmis JN, Ayliffe MA, Huang CY, Martin W. Endosymbiotic gene transfer: organelle genomes forge eukaryotic chromosomes. Nat Rev Genet. 2004;5(2):123-35.

28. Kode V, Mudd EA, lamtham S, Day A. The tobacco plastid accD gene is essential and is required for leaf development. Plant J. 2005;44(2):237-44.

29. Konishi T, Sasaki Y. Compartmentalization of two forms of acetyl-CoA carboxylase in plants and the origin of their tolerance toward herbicides. Proc Natl Acad Sci U S A. 1994;91(9):3598-601.
30. Harris $M E$, Meyer $G$, Vandergon T, Vandergon VO. Loss of the acetyl-CoA Carboxylase (accD) gene in Poales. Plant Mol Biol Report. 2013;31:21.

31. Hiratsuka J, Shimada H, Whittier R, Ishibashi T, Sakamoto M, Mori M, Kondo C, Honji Y, Sun CR, Meng BY, et al. The complete sequence of the rice (Oryza Sativa) chloroplast genome: intermolecular recombination between distinct tRNA genes accounts for a major plastid DNA inversion during the evolution of the cereals. Mol Gen Genet. 1989;217(2-3):185-94.

32. Goremykin W, Holland B, Hirsch-Ernst Kl, Hellwig FH. Analysis of Acorus Calamus chloroplast genome and its phylogenetic implications. Mol Biol Evol. 2005;22(9):1813-22.

33. Rousseau-Gueutin M, Huang $X$, Higginson E, Ayliffe M, Day A, Timmis JN. Potential functional replacement of the plastidic acetyl-CoA carboxylase subunit (accD) gene by recent transfers to the nucleus in some angiosperm lineages. Plant Physiol. 2013;161(4):1918-29.

34. Guisinger MM, Kuehl JV, Boore JL, Jansen RK. Genome-wide analyses of Geraniaceae plastid DNA reveal unprecedented patterns of increased nucleotide substitutions. Proc Natl Acad Sci U S A. 2008;105(47):18424-9.

35. Lee HL, Jansen RK, Chumley TW, Kim KJ. Gene relocations within chloroplast genomes of Jasminum and Menodora (Oleaceae) are due to multiple, overlapping inversions. Mol Biol Evol. 2007;24(5):1161-80.

36. Molina J, Hazzouri KM, Nickrent D, Geisler M, Meyer RS, Pentony MM, Flowers JM, Pelser P, Barcelona J, Inovejas SA, et al. Possible loss of the chloroplast genome in the parasitic flowering plant Rafflesia lagascae (Rafflesiaceae). Mol Biol Evol. 2014;31(4):793-803.

37. Gornicki P, Faris J, King I, Podkowinski J, Gill B, Haselkorn R. Plastid-localized acetyl-CoA carboxylase of bread wheat is encoded by a single gene on each of the three ancestral chromosome sets. Proc Natl Acad Sci U S A. 1997:94(25):14179-84.

38. Konishi T, Shinohara K, Yamada K, Sasaki Y. Acetyl-CoA carboxylase in higher plants: most plants other than gramineae have both the prokaryotic and the eukaryotic forms of this enzyme. Plant Cell Physiol. 1996;37(2):117-22.

39. Cosner ME, Raubeson LA, Jansen RK. Chloroplast DNA rearrangements in Campanulaceae: phylogenetic utility of highly rearranged genomes. BMC Evol Biol. 2004:4:27.

40. Knox EB, Palmer JD. The chloroplast genome arrangement of lobelia thuliniana (Lobeliaceae): expansion of the inverted repeat in an ancestor of the Capanules. Plant Syst Evol. 1999;214:49-64.

41. Cheon KS, Kim KA, Jang SK, Yoo KO. Complete chloroplast genome sequence of campanula takesimana (Campanulaceae), an endemic to Korea. Mitochondrial DNA. 2014;27(3):2169-71.

42. Cheon KS, Yoo KO. Complete chloroplast genome sequence of Hanabusaya asiatica (Campanulaceae), an endemic genus to Korea. Mitochondrial DNA. 2014:27(3):1629-31.

43. Kim KA, Cheon KS, Jang SK, Yoo KO. Complete chloroplast genome sequence of Adenophora remotiflora (Campanulaceae). Mitochondrial DNA. 2015;27(4):2963-4.

44. Wang M, Cui L, Feng K, Deng P, Du X, Wan F, Weining S, Nie X Comparative analysis of Asteraceae chloroplast genomes: structural organization, RNA editing and evolution. Plant Mol Biol Report. 2015:33: 1526

45. Michaud M, Cognat V, Duchene AM, Marechal-Drouard L. A global picture of tRNA genes in plant genomes. Plant J. 2011;66(1):80-93.

46. Rogalski M, Karcher D, Bock R. Superwobbling facilitates translation with reduced tRNA sets. Nat Struct Mol Biol. 2008;15(2):192-8.

47. Besendahl A, Qiu YL, Lee J, Palmer JD, Bhattacharya D. The cyanobacterial origin and vertical transmission of the plastid tRNA(Leu) group-I intron. Curr Genet. 2000;37(1):12-23.

48. Lee J. Gene clusters and introns of Spirogyra maxima chloroplast and other charophytes and their phylogenetic implications in green plants. The Ph.D. Thesis at Texas A\&M University; 1997.

49. Lee J, Manhart JR. Four embryophyte introns and psbB operon explains Chlorokybus as a basal lineage of streptophytes. Algae. 2002;17:53-8.

50. Lee J, Manhart JR. The chloroplast rpl23 gene cluster of Spirogyra Maxima (Charophyceae) shares many similarities with the angiosperm rpl23 operon. Algae. 2002;17:59-68.

51. Fukuzawa $H$, Kohchi T, Sano T, Shirai $H$, Umesono $K$, Inokuchi $H$, Ozeki $H$, Ohyama K. Structure and organization of Marchantia Polymorpha chloroplast genome. III. Gene organization of the large single copy region from rbcL to trnl(CAU). J Mol Biol. 1988;203(2):333-51.

52. Grewe F, Guo W, Gubbels EA, Hansen AK, Mower JP. Complete plastid genomes from Ophioglossum Californicum, Psilotum Nudum, and Equisetum Hyemale 
reveal an ancestral land plant genome structure and resolve the position of Equisetales among monilophytes. BMC Evol Biol. 2013;13:8.

53. Lin CP, Wu CS, Huang YY, Chaw SM. The complete chloroplast genome of Ginkgo Biloba reveals the mechanism of inverted repeat contraction. Genome biology and evolution. 2012;4(3):374-81.

54. Delannoy E, Fujii S, Colas des Francs-Small C, Brundrett M, Small I. Rampant gene loss in the underground orchid Rhizanthella gardneri highlights evolutionary constraints on plastid genomes. Mol Biol Evol. 2011;28(7):2077-86.

55. de Vries J, Sousa FL, Bolter B, Soll J, Gould SB. YCF1: a green TIC? Plant Cell. 2015;27(7):1827-33.

56. Rockenbach K, Havird JC, Monroe JG, Triant DA, Taylor DR, Sloan DB. Positive selection in rapidly evolving plastid-nuclear enzyme complexes. Genetics. 2016;204(4):1507-22.

57. Wyman SK, Jansen RK, Boore JL. Automatic annotation of organellar genomes with DOGMA. Bioinformatics. 2004;20(17):3252-5.

58. Lowe TM, Eddy SR. tRNAscan-SE: a program for improved detection of transfer RNA genes in genomic sequence. Nucleic Acids Res. 1997;25(5):955-64.

59. Laslett D, Canback B. ARAGORN, a program to detect tRNA genes and tmRNA genes in nucleotide sequences. Nucleic Acids Res. 2004;32(1):11-6.

60. Conant GC, Wolfe KH. GenomeVx: simple web-based creation of editable circular chromosome maps. Bioinformatics. 2008;24(6):861-2.

61. Darling AE, Mau B, Perna NT. progressiveMauve: multiple genome alignment with gene gain, loss and rearrangement. PLoS One. 2010;5(6):e11147.

62. Jeong H, Lim JM, Park J, Sim YM, Choi HG, Lee J, Jeong WJ. Plastid and mitochondrion genomic sequences from Arctic chlorella sp. ArM0029B. BMC Genomics. 2014;15:286.

\section{Submit your next manuscript to BioMed Central} and we will help you at every step:

- We accept pre-submission inquiries

- Our selector tool helps you to find the most relevant journal

- We provide round the clock customer support

- Convenient online submission

- Thorough peer review

- Inclusion in PubMed and all major indexing services

- Maximum visibility for your research

Submit your manuscript at www.biomedcentral.com/submit 